(D)

CORPUS PUBLISHERS

\section{Environmental}

Sciences and

\section{Ecology: Current Research (ESECR)}

Volume 2 Issue 6, 2021

Article Information

Received date: November 03, 2021

Published date: November 16, 2021

${ }^{*}$ Corresponding author

L Ponyaev, Moscow Aviation Institute,

4, Volokolamskoe, shosse, Moscow,

125993, Russia

\section{Keywords}

Airlines Cargo; Ecology Efficiency; LongHaul Aircrafts; Computer Digital Aircraft; Lift Fuselage; Dialectical Contradiction

Distributed under Creative Commons CC-BY 4.0

\title{
Development of the Low Toxic Cross Polar Air Transport using Innovative Hydrogen Projection for Large Aircraft and Airships
}

L Ponyaev ${ }^{1 *}$, N Kuprikov ${ }^{1}$, M Kuprikov ${ }^{1}$ and N Gebhardt $^{2}$

${ }^{1}$ Moscow Aviation Institute, Volokolamskoe shosse, Russia

${ }^{2}$ Innovation Park Innovare, Innovaare AG, Switzerland

The new shortly and low cost Regular Airlines Cargo \& PAX directions via Arctic Cross Polar Air Transportation Routes of the future High Ecology Efficiency and Safety ICAO Strategy will be base on the more perspective for Trans Continental Airlines Operations by IATA International Law Regulations and World Climate Protect Law. Using the more shortly directions of Trans Polar Flight for Long-Haul Aircrafts (LHA) Routes by leader Airlines Sky Teams with Aeroflot are request to find new Geometrical Layout of Aircraft Design Industrial Projections \& Products Lines. The increase in the dimension of LHA came into conflict with modern Airport Infrastructure and led to the search for alternative Arctic Planes \& Dirigibles Options for constructively layout circuit solutions with protection of minimum weight and drag issues in order to deal with this contradiction. Computer Digital Aircraft Structural-Parametric Analysis of the influence of Aviation Infrastructure Constraints in the basing of LHA on the choice of alternative Design Options for Lift Fuselage Body or Flying-V layout was carried out.

Introduction

The new Cross Arctic Ait Transport Routes will be priority focusing to the more shortly Cross Polar Transcontinental Directions from USA-Canada via Russia-Yakutia to Asia-Singapore. For minimize influence to Ecology CO Pollution and Noise Level of Fuel-Engine Power we are going to find the optimal new Geometry of the Large Aircraft and E-Airships. The famous Aircraft Conceptions and Dialectical Contradiction between the constantly improving new types of future Aircraft Design and the continuously aging Airport Hub Infrastructure arose from the very first days of the advent of Aviation and it is of a fundamental R\&D strategy. Transition to transonic and supersonic flight speeds, an increase in PAX \& Cargo flows and, as a result, an increase in the Dimension of Aircraft, led to the emergence of a powerful, expensive infrastructure complex [1]. The Aircraft Fleet and the Airport Hub Infrastructure are a single interconnected Air Transport System. The creation of a modern Airport Hub requires a land area of more than $8 \mathrm{~K}$ hectares, artificial runway cover, taxi ways, huge time and service expenditures. For a certain class of Aircraft, one can distinguish a group of limitations that are conceptual in nature and have a priority influence on the generating process of Aircraft Conceptual Design (ACD). The Global Infrastructures of Worldwide may be more efficiency involved, as example, the Thailand City Airport Hub to priority Airlines flights to EC, USA, Latin America and South Africa. A significant impact on the satisfaction of Infrastructure Requirements is provided by structural and layout solutions. The ACD taking into account the infrastructure requirements, will allow them to be taken into account in the early Stages of Aircraft Design [2]. (Figure 1) shows the aircraft in the Limiting Space of infrastructure constraints.

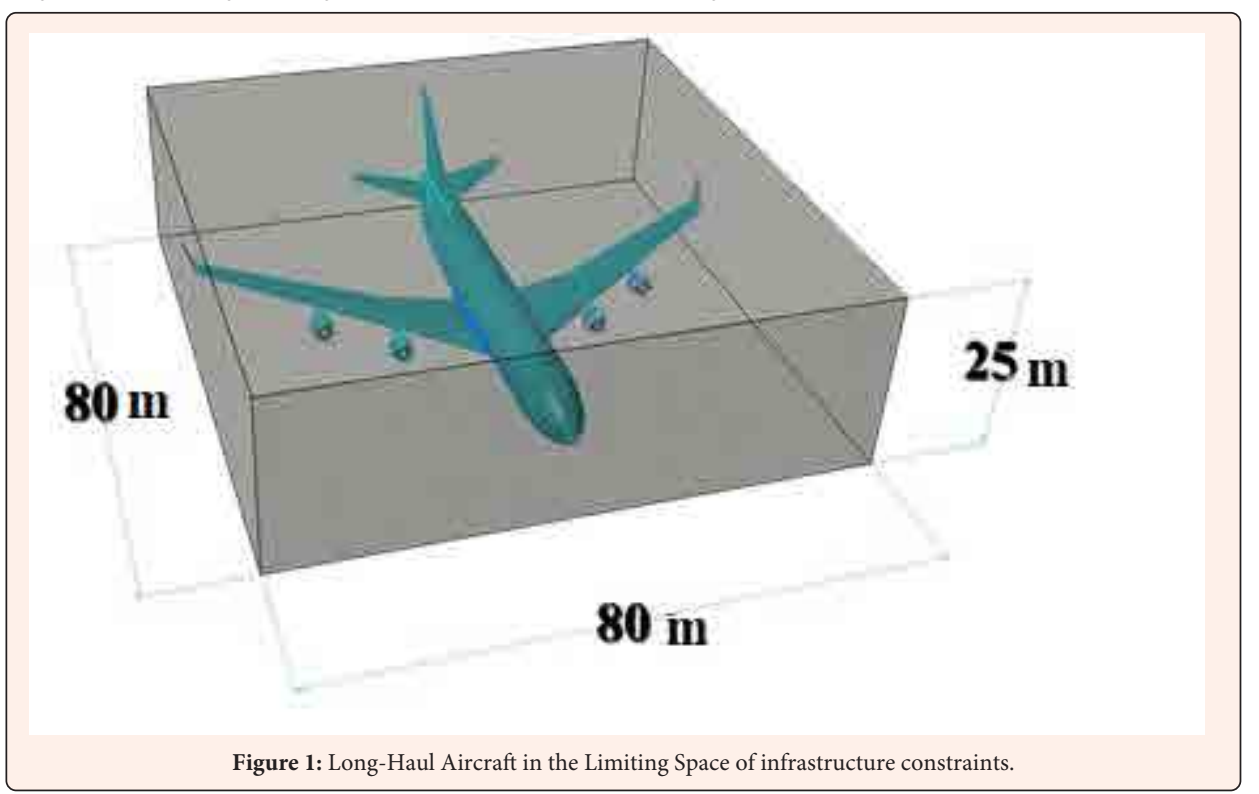

The solution of the problem of the ACD as a problem of mathematical Digital Modeling Software by CATIA5 of CAD/ CAM/CAE System [3] does not always lead to success because of the considerable dimensionality of the vector of constructive parameters $\mathrm{X}^{*}$, the complexity of the set of constraints $\mathrm{U}$, as well as the large time required to compute the objective function 
vector. Therefore, the correctness of the decomposition of the vector system of target functions, project parameters and constraints is very important. This circumstance is connected with the fact that the layout of the Aircraft is the result of a compromise solution of design tasks, which is typical for new versions and patenting conceptual design with focus to improve the Airport HUB Service Level and minimum maintenance operations as show on (Figure 2).

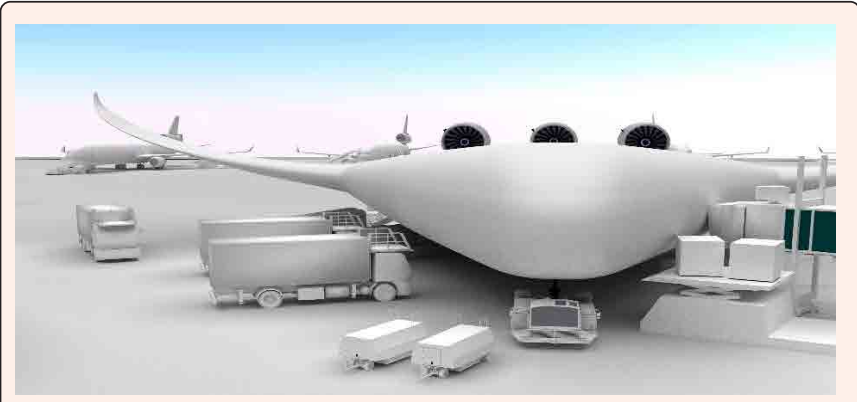

Figure 2: Optimization Airport HUB Service for PAX \& Cargo operations.

Features of the Aircraft Conception Optimal Design

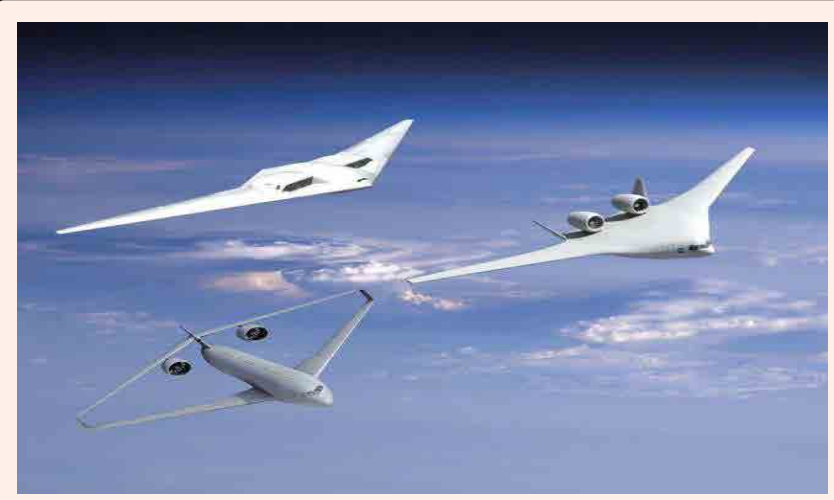

Figure 3: The new Optimal Design of Aircraft: a-concepts of Flying Wing, Wing Body and Romb Shaped, and, b-Disc Wing Concept for STOL Operation in City HUB Airports.

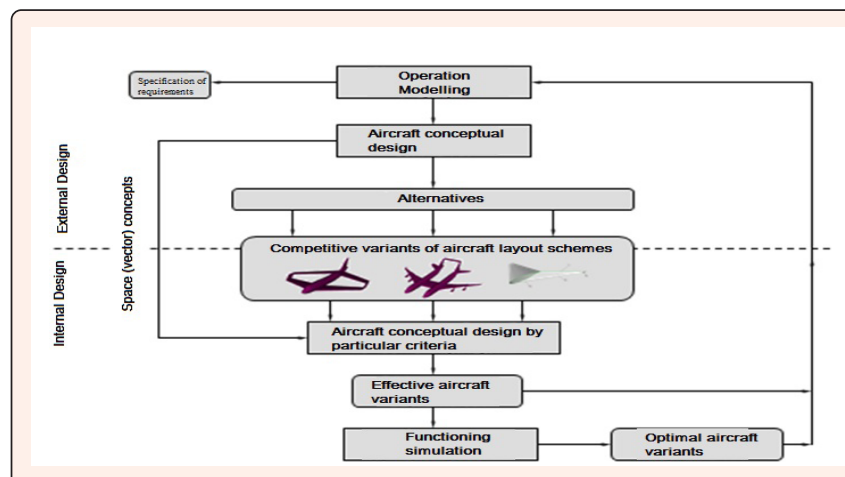

Figure 4: Optimal Math Model of the Long-Haul Aircraft conceptual Design Strategy Version.

As new complex Analysis of the Aircraft Design ideology goals are focus to the Integrate 3D Projections as Body Plane or Body Wing Aerodynamic Complex with minimum Drag, Fuel Consumption and Noise/Sound Level during the all Flight Operation in the Sky. An important feature of ACD process is the dominance of certain particular criteria over others and the increase in the importance of certain particular criteria to the level of General Criteria. The solution of the "Direct" Design problem of the Aircraft leads to a multi-iterationr, and, consequently, to significant time and material expenditures. In this connection, the solution model of the "inverse" problem of Aircraft Design acquires particular interest, i.e., the situation when the rational values of the parameters correspond to the permissible the Minimum, or the Maximum value of the characteristic, which uniquely follows from the set of constraints, see any versions on (Figure 3). The problems of this type are characterized by a fairly frequent absence of points of the Function Optimums in the interval under consideration and a smooth gradient of its growth [4].

The conducted researches have shown that for different types of Aircraft the nomenclature of constraints is practically equivalent as view on (Figure 4). However in absolute terms, constraints are not always critical. The analysis of constraints allows us to formalize them in scalar and in functional form. These requirements are formed at the stage of External Design, and at the stage of Internal Design they are specified in the specification of the main Technical Requirements. The analysis of the variety of infrastructure constraints and requirements shows that they can be systematized and classified according to the five characteristics presented in (Table 1).

Table 1: Infrastructural requirements for Aircraft Criteria Complex Analysis.

\begin{tabular}{|c|c|c|c|c|}
\hline No. & Criteria Type & $\mathbf{1}$ & $\mathbf{2}$ & $\mathbf{3}$ \\
\hline U1 & $\begin{array}{c}\text { Basing (landing } \\
\text { field) }\end{array}$ & Runway length & Runway width & $\begin{array}{c}\text { Runway } \\
\text { strength }\end{array}$ \\
\hline U2 & $\begin{array}{c}\text { Service processing } \\
\text { area }\end{array}$ & $\begin{array}{c}\text { Dimensions of } \\
\text { the terminal }\end{array}$ & $\begin{array}{c}\text { Dimensions of } \\
\text { parking spaces }\end{array}$ & $\begin{array}{c}\text { Dimensions } \\
\text { of transport } \\
\text { areas }\end{array}$ \\
\hline U3 & $\begin{array}{c}\text { Maintenance } \\
\text { and operational } \\
\text { technological } \\
\text { effectiveness }\end{array}$ & $\begin{array}{c}\text { Loading and } \\
\text { unloading of the } \\
\text { target load }\end{array}$ & $\begin{array}{c}\text { Inspection and } \\
\text { refueling }\end{array}$ & Reparability \\
\hline U4 & Ecology & Noise/Sound & Temperature & Toxicity \\
\hline & & & & Radioactivity \\
U5 & $\begin{array}{c}\text { Regional and } \\
\text { demographic factor }\end{array}$ & MCA & Biosphere & fields \\
\hline
\end{tabular}

Many infrastructure constraints either directly or indirectly influence on the choice of the main parameter values and the dimension of the Aircraft. The influence of infrastructure requirements on the dimension of the Aircraft will be considered through the example of factors for which it is critical. The Demographic Global Factor (DGF) of infrastructure requirements developed historically and is the objective background that determines the location of Aviation Infrastructure in each individual World Continental Region and on the globe as a whole. Due to the requirements specified in the specification of requirements, that the Aircraft must meet, the DGF for some types of Aircrafts becomes decisive. Typical representatives of such Hub Airports are the famous Bangkok, London, New York, etc. This circumstance does not allow increasing the length of the runway and it requires an improvement in the take-off and landing characteristics. One way to improve the take-off and landing characteristics is to either reduce the specific load on the wing, the Engines on down or upper wing with low vibration load and sound inside/outside PAX Cabin or increase the thrust-to-weight ratio of the Aircraft.

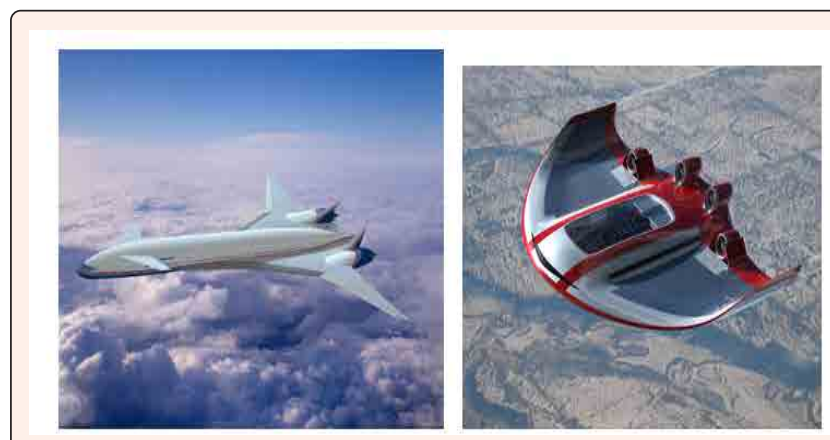

Figure 5: Aircraft Design Concepts: a-Canard Integrate Shema and b-Disc Shaped Vision.

Citation: Ponyaev L, Kuprikov N, Kuprikov M, Gebhardt N (2021) Development of the Low Toxic Cross Polar Air Transport using Innovative Hydrogen Projection for Large Aircraft and Airships. Environ Sci Ecol: Curr Res 2: 1037 
The number of parameters characterizing the influence of noise reduction and emission minimize requirements on the terrain during the operation of the Aircraft is generally large, but they can be reduced to the relative parameters of the Aircraft, which enter into the equations characterizing the flight level, technical facility, aerodynamic efficiency and other characteristics as vision on the (Figure 5). As parameters for deterministic search for rational values, it is necessary to use general Aircraft parameters and functional criteria. So, almost unequivocally, it can be argued that, other things being equal, it is necessary to reduce the take-off mass, the area of the washable surface, the thrust and the number of engines, etc. Consequently, as the parameters for minimizing the take-off mass, one can consider the specific load on the wing and the thrust-to-weight ratio of the Aircraft.

The Minimize Dimension and Weight of a Long-Haul Aircraft to the New Airport HUB Infrastructure

The complex analysis let's consider the influence of infrastructure constraints on the dimension of a LHA Optimal Design Vision. Under the conditions of increased competition between manufacturers, much attention is paid to the Stage of promising construction and layout schemes and the search for new Concept Design and new Composite Material construction solutions, since it is a question of designing new types of Aircraft that have no analogues or prototypes. As alternative circuit solutions, along with the traditional Normal as Classic Aerodynamic balancing Scheme of the Aircraft, others are considered that have two distinct trends: to an increase in the number of bearing surfaces-Tree Plane or to their decrease-Flying Wing or any versions of Twin Body-Rombus-Disc Conceptions with Local Engines between Fuselages on upper surface of Wing. The main distinguishing feature of the LHA with large passenger capacity is a very significant geometric and mass dimension of the Aircraft. This feature is in conflict with a number of factors of the infrastructure already existing today. The Flight operation of Aircrafts must be carried out on the existing network of Airports, which imposes on them a number of infrastructure constraints, such as: the length and width of the runway, the width and steering radius of the taxi ways, the distance from the wing console to the slot hand-buildings, the distance between the consoles of aircraft wings on parallel taxi ways and runways, the strength of the runway cover, etc. As an example for high-class Airports, the considered characteristics of the basing of the LHA with large passenger capacity are analyzed in Aircraft Engineering Graphics and CAD Department of the MAI University. The structural and parametric analysis of high-class Hub Airports allows us to Identify the Infrastructure Requirements for LHA and form a vector of constraints $\mathrm{U}=\mathrm{U}$ (ui), which characterizes the Aircraft Conceptual Design problem of the LHA with large passenger capacity:

$$
\begin{gathered}
\mathrm{u} 11=\mathrm{u}(\text { Lrunway }<3000 \mathrm{~m}) \\
\mathrm{u} 12=\mathrm{u}(\text { Brunway }<60 \mathrm{~m}) \\
\mathrm{u} 13=\mathrm{u}(\mathrm{ACN}<65)
\end{gathered}
$$

Analysis of Infrastructure Factors shows their impact on the dimension of the Aircraft. The main indicator of the dimension of the Aircraft is its take-off mass. At the stage of determining the dimension of the Aircraft, it is determined by the weight balance equation:

$$
\mathrm{maf}+\mathrm{meu}+\mathrm{mec}+\mathrm{mf}+\mathrm{mt}+\mathrm{msl}=\mathrm{M}
$$

where maf-air frame mass; meu-engine unit mass; mec-mass of equipment and control; mf-mass of fuel; mtl-mass of given target load; msl-mass of service load and equipment. Solving the weight balance equation with respect to the take-off mass, we can determine its value in the first approximation. Data on the relative masses of the structure and engine unit are taken from the statistics, and the target load, inventory and equipment are given in the specification of requirements in absolute value. An example of the influence of infrastructure restrictions on the dimension of an Aircraft through the masses of elements is the dependence of the relative mass of fuel from the range of flight (demographic factor), which is determined by the Breguet formula. At the layout stage, the three unique problem of the Aerodynamic, Volume-weight and Structuralforce layouts is solved. The stage of synthesis of the layout scheme is aimed at resolving the contradictions of the internal layout and the formation of the external contours of the Aircraft. When considering the impact of "hard" infrastructure requirements on the Aircraft layout, it can be seen that they form a Conceptual Description of the Object. However, its meaningful content depends on the purpose of the Aircraft and, as a consequence, the criticality of certain constraint. In order to minimize the number of the Comp-Digital Iterations of the layout, it is necessary to identify a critical factor and to build the layout procedures into a single algorithm with respect to it. In this case, the implementation of the "reverse" layout task begins with the identification of the layout space and its decomposition according to the characteristic features. As the latter, there are signs that are uniquely determined by infrastructural requirements (Dimensions) and more multivalued signs (Alignment, moments of inertia, specific density, etc.) Characteristic features carry a conceptual component both for individual units and for the Aircraft in general. Implementation of the layout procedures with respect to the Critical Factor leads to the decomposition of layout procedures and the identification of the order of their execution.

The perspective Design Concept of Disc Shaped Solar E-Airship for Decrease Weight and Vibration Loads

The Aerodynamics of Discs Shaped Aircraft and Airship has not been estimated yet, but several dozen of projects are known. It's the MAI Light-then-Air (LTA) Disc Shaped THERMOPLANE as view on Figure 6 is the unique and patented Project or other version as the Ellipse Shaped EKIP Project with the new Laminar Flow Control and Solar Nano Film Upper Surface System for more Electrical Sky ships for Flight and Rescue Operation along the Cross Polar Routs of LHA as High Ecology Air Transport Aircraft \& Airship conceptions to Future Mobility Development [5].
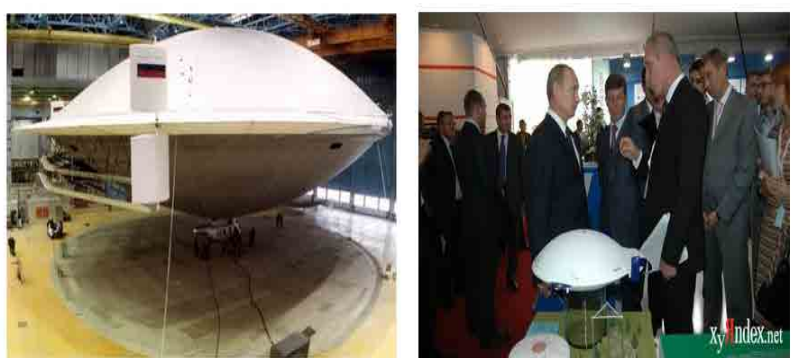

Figure 6: The patented Disc Shaped LTA: a-THERMOPLANE Project by MAI Design and b-visit. President Putin VV to the AVIASTAR Plant in Ulyanovsk where produced THERMOPLANE.

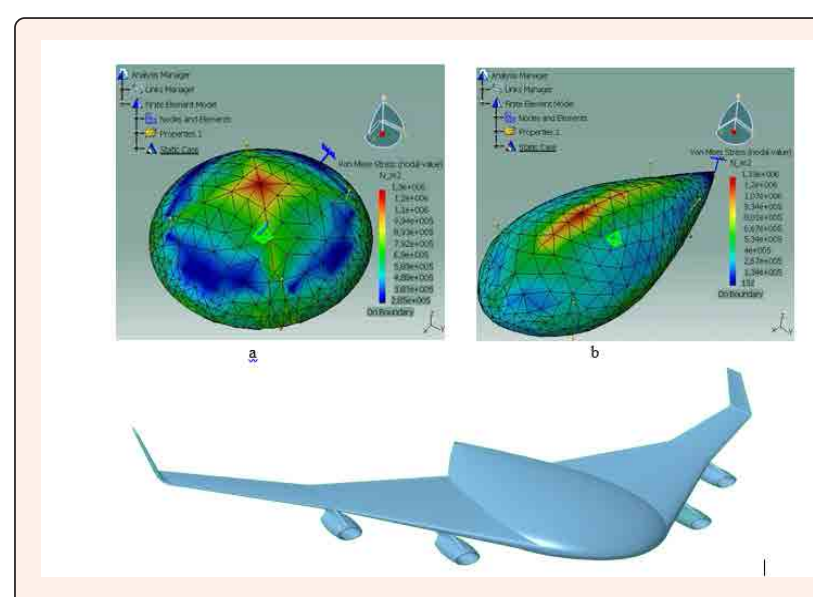

Figure 7: The Design Analysis Geometry: a-Disc and b-Drop Shape of the bearing fuselage and the washable surface of the Aircraft made according to c-the Integral Forms of Wing Body Plane.

The Hybrid Electric LHA are focused to a Long Time of Sky flight, so a high priority in the formation of the washable Disc Solar Energy surface is a High Aerodynamic Quality. And it is the higher, the lower the resistance and the greater the bearing capacity is (Figure 7) shows the Drop shape of the bearing fuselage and the washable surface of the Aircraft made according to the more efficiency Integral Formation. The structuralparametric analysis of the stress-strain state shows a pronounced anomalous zone. To compensate it, a power longitudinal element separating of the Spherical Polar Geometry Methods to Disc or Drop-Shaped fuselage Structure Composition into two symmetrical segments is needed [6]. The value of the Global Criterion of comparative characteristics of Emergency Evacuation of Aircraft passengers and crews, obtained by the Methodology of Professor M. Akopov by convolving seventeen Particular Criteria through weighting coefficients for LHA- 5 was $\mathrm{V}=0.634$, which is much better than the values of the Global 
Criterion for all other layouts. So, in comparison with the base Aircraft of a Normal Aerodynamic Scheme, the Global Criterion is better by 1.78 times, and in comparison with the Canard-Rombus or Tree Plane Scheme with an articulated wing-2.39 times. In comparison with the base Aircraft of a Normal Aerodynamic Scheme with minimum Ecology influence by Sound/Noise and Toxic/Vibration, the Low Cost of a flight hour is $84 \%$, and in comparison with a Tree Plane Scheme with an articulated wing- $94 \%$. The advantages of Aircrafts designed according to the Flying Wing Scheme in relation to other Schemes rise with the increase in the Dimension of the Aircraft. The greater value of the target load and the flight range is the better application of this Optimal Aerodynamic Scheme.

\section{Conclusion}

The strategy Innovation Aircraft and Airship Concepts are focus to new optimal Design as requirement to Trans-Siberian and Arctic Air Transportation Corridors future. The Computer Digital Structural \& Parametric Analysis of the influence of infrastructural requirements on the 3Dimention Complex Synthesis of Long-Haul Aircraft and Solar Disc Shaped Airship Projection to use also More Electrical Power Systems with large passenger capacity confirms the fundamental possibility of creating an Aircraft \& Airship of this type for Ecology and Economically Efficient Operation Life Time in an already Existing Airport/HUB Infrastructure complex and Cross Polar shorter Trans Continental Routes are demonstrates possible directions for the Development of this type of main progress future Aviation \& Airship Complex Design, Digital Factory of Robotic HQ Produce and Safety Flight Operations in the Open Sky Polar International Regions by new actions of the ICAO/IATA Global Ecology Regulation Strategy.

\section{References}

1. Dolgov O, Kuprikov M 2008) Momento-inertial factor in the formation of the shape of the Aircraft. Moscow: MAI-PRINT Publishing House 180.

2. Dolgov O, Kuprikov M, Kuprikov N (2010) Features of detecting the momentinertial appearance of perspective aircraft, in the early stages of design Bulletin of the Moscow Aviation Institute 2 (17): 1-4.

3. Dolgov O, Kuprikov M, Ripetsky A (2010) Features of geometric synthesis at different stages in the formation of the shape of a large passenger capacity aircraft. Bulletin of the Moscow Aviation Institute 5(17): 43-48.

4. Kuprikov M, Maksimov S (1999) Influence of infrastructure restrictions on the appearance of a long-range aircraft. News of universities Aviation equipment 5255

5. Ponyaev L (1997) Thermoplane ALA-40/ALA-600, Catalog Brassey's World Aircraft \& System Directory 545.

6. Ponyaev L (2018) Scientific Technologies, S\&P Journal PSSN 223-2966 Moscow, Russia, Natural \& Technical Science 9: 60-65 